\section{How deep is an 'ozone hole'?}

SIR-We wish to comment on the figures for Antarctic ozone depletion quoted by David Lindley (Nature 335, 657; 1988), and based on TOMS (total ozone mapping spectrometer) measurements from the Nimbus-7 satellite.

TOMS maps show that the core of the polar stratospheric vortex, in which depletion is most marked, varies rapidly in shape and position, making it difficult to select any one parameter as a measure of the depth of the 'ozone hole'. The figures given by your correspondent refer to September alone (TOMS cannot retrieve ozone values from the polar cap in July and August). The figure below shows, for comparison, provisional ozone amounts

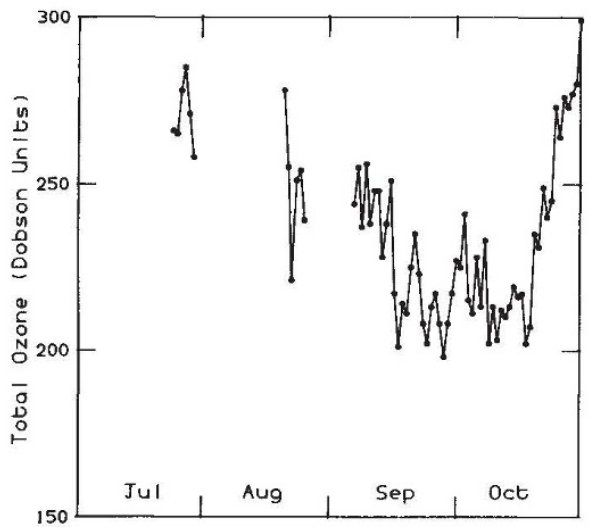

Ozone values at Halley in 1988.

reported to us by our station at Halley Bay. A rough guide to the severity of depletion is given by the difference between values in July and August, and the least values seen in early October, corresponding to a depletion of about 26 per cent. This is similar to that recorded at Halley Bay in 1984 (ref. 1), but less than in 1985, 1986 and 1987.

The vortex has been centred over West Antarctica since early September, and has been elliptical rather than circular (the wave-number one component has been larger than usual, and relatively steady; the wave-number two component has also been large, and has undergone rapid phase progression). Warm air, and high ozone amounts, were established over East Antarctica in late September, and the vortex is now being displaced towards the Atlantic in the course of what appears to be the final warming. The cold core is now passing over Halley Bay. It still contains ozone-poor air; the increase in column ozone seen in late October arises mainly from transport at higher altitudes, above $20 \mathrm{~km}$.

If the strong subsidence seen earlier over East Antarctica continues into West Antarctica as the vortex moves away, the depletion in 1989 could be very deep. The subsided air, rich in ozone and inorganic chlorine compounds, and poor in chloro- fluorocarbons (CFCs) and nitric oxide $\left(\mathrm{N}_{2} \mathrm{O}\right)$, will become in the ensuing months next year's polar vortex. Ozone amounts will decay photochemically during the summer, but the inorganic chlorine will persist. The altitude structure of the $\mathrm{CFC}$ and $\mathrm{N}_{2} \mathrm{O}$ distributions seen in the Airborne Antarctic Ozone Experiment last year will be imposed during the spin-up of the vortex. However, the subsidence in the winter is weak, as may be inferred by the absence of significant changes in ozone amount, and the total amount of inorganic chlorine will remain essentially unaltered.

The extent to which this inorganic chlorine will yield active chlorine in the spring of 1989 will, of course, depend on the temperatures and amounts of polar stratospheric clouds which then prevail. Looking back, the weak depletion of 1988 was determined, at least in part, by the late final warming of 1987 , and the weak subsidence which accompanied it. Inorganic chlorine which had subsided earlier into the warm belt was diluted before moving across Antarctica to develop into the 1988 vortex.

Mark Schoeberl, according to Lindley, attributes much of the year-to-year variation in the depth of the 'ozone hole' to the quasi-biennial oscillation (QBO) of the tropical stratosphere. This seems premature. While it is easy to see that the QBO can modulate planetary wave propagation, it seems doubtful whether it controls planetary wave generation, essentially a tropospheric process. It is not unlikely that the strong variations seen in the past few years are largely fortuitous, and that a phase change, independent of the QBO, might well appear.

J. C. FARMAN

B. G. GARDineR

J. D. SHANKLiN

British Antarctic Survey,

High Cross, Madingley Road,

Cambridge CB3 OET, UK

I. Farman, J.C., Gardiner, B.G. \& Shanklin, J.D. Nature 315 . 207-210(1985).

\section{Industrial disease?}

SIR-The news item "Changing relationship seen in new corporate-university ties" (Nature 335, 106; 1988), misses the real reasons for this trend.

Funding is not the issue: rather the issues are research and development costs and patenting and licensing of innovations and inventions. In 1985, the federal government, industry, and academic institutions supplied $\$ 52,003$ million, $\$ 49,863$ million, and $\$ 2,286$ million in $\mathrm{R} \& \mathrm{D}$ funds, respectively (1982 dollars) (Statistical Abstract of the US: 1988). Yet they performed $\$ 12,698$ million, $\$ 76,956$ million and $\$ 9,439$ million in $\mathrm{R} \& \mathrm{D}$, respectively (1982 dollars). Both industry and academic institutions receive large transfer payments from the federal government in the form of contracts. Despite industry's windfall, problems with intellectual property rights are endemic in governmentindustry science projects. Patenting and licensing is limited in these joint ventures, reducing profit potential.

Also, in 1985 for example, the average full-time equivalent cost per scientist or engineer was $\$ 140,500$, whereas the average graduate student made between $\$ 10,000$ and $\$ 15,000$ per year. Industry, in an effort to reduce costs, decided that it was better to have graduate students perform the $\mathrm{R} \& \mathrm{D}$, in the form of $\mathrm{PhD}$ theses, at nearly one-tenth the cost per scientist. Even five graduate students were cheaper than one private scientist. Bonuses for industry from joint ventures with academic institutions are greater bargaining power and fewer intellectual property restrictions. This position is much more profitable than that with government.

These facts seem to explain very nicely the growing number of industrial-academic cooperation agreements. As an MIT graduate student, I too fear the loss of academic freedom, as well as the exploitation of graduate students at relatively low wages, with no or few proprietary rights.

DAVID WAGgER

29 Park Drive, Apt 1 ,

Boston, Massachussetts 02215, USA

\section{Embryo definitions}

SIR-Acceptable scientific terminology must aim to be universal and objective. Its integrity must not be compromised for administrative or legal convenience, or to evade ethical considerations. Nonetheless Braude et al. ${ }^{1}$ have repeated their presumption in employing once again the term "preembryo" as a scientific descriptive, even though their own earlier work had demonstrated the arbitrary nature of the "pre"-fix ${ }^{2}$. It is therefore necessary to re-emphasize that the term was synthesized in the United Kingdom precisely to avoid possible legal restrictions in that jurisdiction on research on human embryos at their earliest stages of development. This lawyer's stratagem cannot constitute a scientific definition. Neither can a voluntary coalition of interested parties assert itself as a 'regulating authority' on ethical issues. Intellectual rigour with precision and objectivity of definition must be maintained, if necessary by the exercise of refereeing and editorial responsibility.

Institut de Chimie Physique,

EPFL-Ecublens,

CH-1015 Lausanne, Switzerland

Braude P Bolton V \& Moore S. Nature 335.392 (1988) 2. Braude P.. Bolton V. \& Moore S. Nature 332. 459 (1988) 